\title{
Osteoporosis and Recurrent Pathological Fractures Associated with Intense Cannabinoid Use: A Case Report
}

Goknur Yorulmaz ${ }^{1}$, Emel Gönüllü ${ }^{2}$, Nazım Karakuş³

1Eskişehir State Hospital, Endocrinology Department

2Eskişehir State Hospital, Rheumatology Department

3Eskişehir State Hospital, Orthopedics and Traumatology Department

\section{INTRODUCTION:}

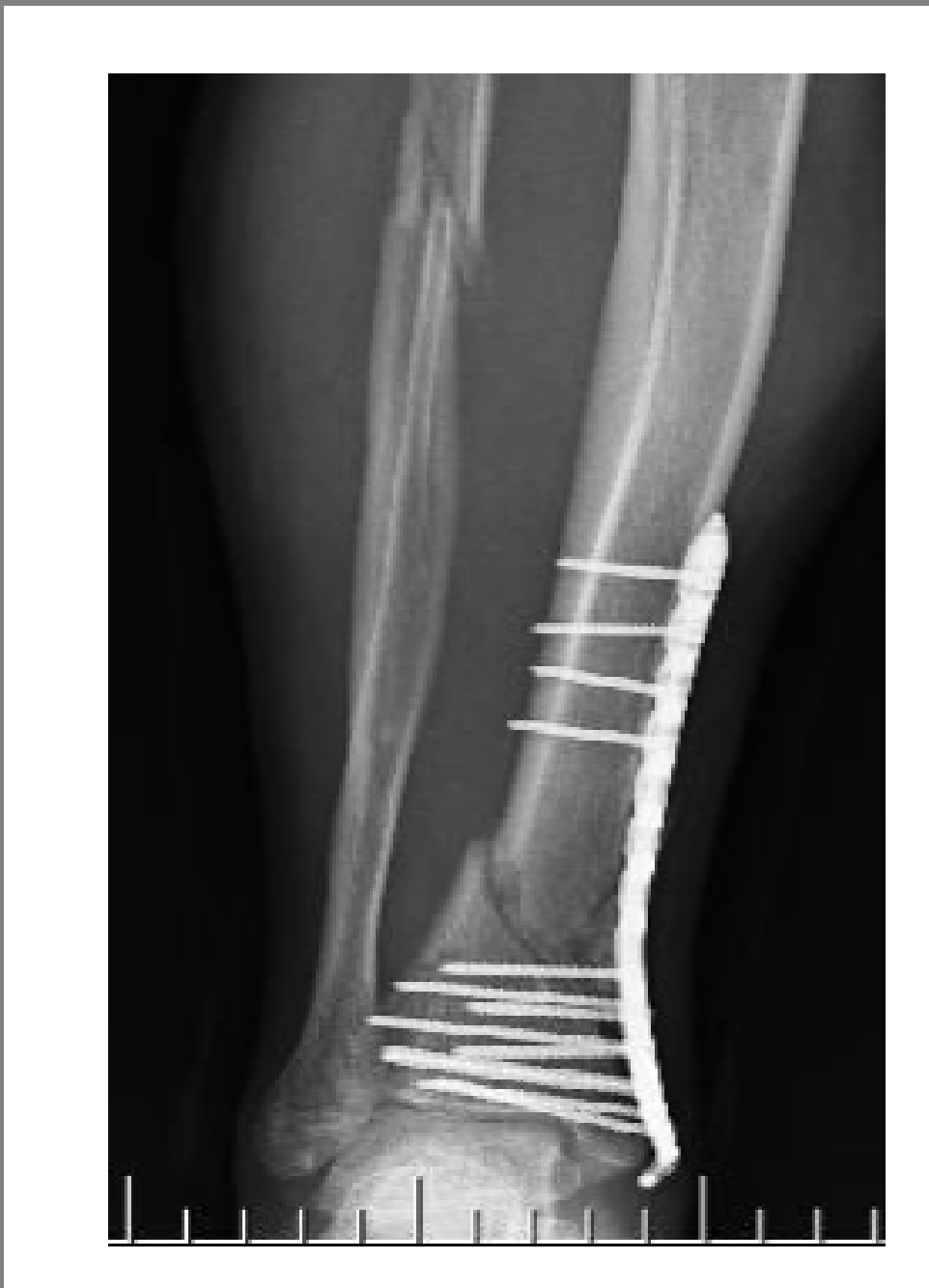

Figure 1: Pathological fractures in the tibia and fibula

\section{CASE:}

\section{CONCLUSION}

\section{REFERENCES:}

Cannabis / marijuana / cannabinoids are the most commonly used illicit drug in the world which can be originated from plants or can be in synthetic forms. Here, an intensive marijuana smoker, 33 years old patient, who has osteoporosis with recurrent pathologic fractures will be presented.

Thirty-three-years-old male patient was referred to the our clinics in order to investigate the causes that may lead a pathologic fracture because the patient had the tibia and fibula fracture without any obvious trauma(Figure 1). The patient's blood calcium, phosphorus, alkaline phosphatase, vitamin D and parathyroid hormone levels were normal. There were no signs and symptoms that can be suggestive of malignancy. Erythrocyte sedimentation rate and C-Reactive protein levels were normal. Bone mineral density was measured with dual-energy $X$-ray absorptiometry (DXA) and T-score of L1$L 4=-2.9, T$-score of the femoral neck=-2.3. We asked him whether he uses any drug for any reason. He answered that he had started to use cannabis when he was fourteen and since then, he has been using the canabinoid as 19-20/day in the form of cigarettes additionally in the form of inhalation and sometimes synthetic forms. He said he had treated for the broken bones (one time for his hand and one time for his foot) twice by an orthopedist before this event. Pathological fractures of the patient were attributed to his intensive cannabis smoking.

Important roles of the cannabinoid receptors during osteoporosis process have been shown by the investigators. We considered our case in cannabinoid-induced osteoporosis.

Bab I, Zimmer A, Melamed E. Cannabinoids and the skeleton: from marijuana to reversal of bone loss. Ann Med. 2009;41:560-7.

Whyte LS, Ford L, Ridge SA, Cameron GA, Rogers MJ, Ross RA. Cannabinoids and bone: endocannabinoids modulate human osteoclast function in vitro.Br J Pharmacol. 2012 Apr;165(8):2584-97. 